\title{
Effect of oral contraceptives on blood pressure and on plasma renin, renin substrate, and corticosteroids
}

\author{
R. J. WEIR, M. TREE, AND R. FRASER \\ From the MRC Blood Pressure Unit, Western Infirmary, Glasgow
}

SYNOPSIS A rise in blood pressure associated with oral contraceptives is well established but the frequency with which it develops is not known. Early results from a controlled long-term prospective study have shown no significant change in mean systolic or diastolic pressures or mean weight in 31 women after four months on oral contraceptives. In no individual subject was there a significant change in blood pressure or weight over the short period of the experiment.

In 10 women, oral contraceptives have been shown to induce a consistent rise in plasma renin substrate and cortisol concentrations after four weeks. At this time plasma renin concentration had fallen slightly in eight out of 10 women but neither plasma aldosterone nor plasma corticosterone showed any consistent response.

Raised blood pressure (above 140/90 mm Hg) associated with oral contraceptives has been reported on several occasions but the incidence of hypertension in women taking these drugs is not known. Changes in renin substrate, renin, and aldosterone secretion and excretion have also been observed, but no direct relationship between these factors and the rise in blood pressure has yet been established. This paper is arranged in two sections: a short review of blood pressure and endocrine changes during the administration of oral contraceptives followed by a preliminary report of a study of their effects on the plasma concentrations of renin, renin substrate, aldosterone, corticosterone, and cortisol.

\section{Effect on Blood Pressure}

A few single cases of hypertension have occurred in women taking oral contraceptive preparations (Brownrigg, 1962; Owen, 1966) and two reports describe hypertension, malignant in one case, developing during this treatment (Dussek, 1969; Harris, 1969). In 1967, Woods reported blood pressures in excess of $140 / 90 \mathrm{~mm} \mathrm{Hg}$ in six patients within six weeks to two years of starting treatment. Four of these women had previously been normotensive (below 140/90 mm Hg) and, after withdrawal of the contraceptive, blood pressure fell to initial levels in three cases within two months. In two women, essential hypertension was aggravated by oral contraception but subsided to initial levels when this was withdrawn.

Laragh, Sealey, Ledingham, and Newton (1967) also found a relationship between the institution of oral contraceptive therapy and the development or enhancement of high blood pressure in eight hypertensive patients, six of whom were known to have been normotensive before treatment. A similar association in six women was reported by Weinberger, Dowdy, Nokes, and Luetscher (1968).

In a retrospective study of the effects of oral contraceptives on the total population taking these compounds, Loudon and Burton (1969) analysed data of three years from 153 cases, and found a mean annual systolic increment of 1.8 $\mathrm{mm} \mathrm{Hg}$ and a diastolic increment of $0.7 \mathrm{~mm} \mathrm{Hg}$, both greater than would be expected from the effects of aging alone. Goodlin and Waechter (1969), in a retrospective review of 120 randomly 
selected women, concluded, however, that no consistent pattern was present over a similar period. A series of 496 contraceptive users were found to have significantly higher mean systolic and diastolic pressure levels than non-users after correction for age, height, weight, and arm circumference, but in a sample after a further year no change in blood pressure was found in either group (Kunin, McCormack, and Abernathy, 1969).

A short prospective study of 43 women with diastolic pressures below $80 \mathrm{~mm} \mathrm{Hg}$ taking Ovulen (ethynodiol diacetate: $1 \mathrm{mg}$, mestranol: $0.1 \mathrm{mg}$ ) was described by Tyson (1968). Of these, six showed a rise in diastolic pressure to $90 \mathrm{~mm}$ $\mathrm{Hg}$ or more after one to four months of treatment, which was reversed in all six within $\mathbf{3 0}$ days of withdrawal of the drug. No abnormal blood pressure changes were found in 120 women of comparable age, followed simultaneously, using an intrauterine contraceptive device. This contrasts with the work of Chernick (1968) who found no statistically significant difference in the proportions of patients with raised blood pressure between a group of 303 women using Orthonovum (norethindrone: $5 \mathrm{mg}$, mestranol: $0.075 \mathrm{mg}$ ) and another of 56 women using an intrauterine contraceptive device for periods of up to the equivalent of 10 menstrual cycles.

In a larger prospective study over two years of some 9,000 patients taking oral contraceptives (Chiddell, 1969) 90 women had blood pressures over $140 / 90 \mathrm{~mm} \mathrm{Hg}, 31$ of whom had levels below this at their first visit to the clinic and 37 of whom were already taking oral contraceptives when the initial blood pressure readings were taken. Fifty per cent of those whose blood pressure was already high $(>140 / 90 \mathrm{~mm} \mathrm{Hg}$ ) showed a further rise on taking the drug. When the drug was withdrawn, $84 \%$ of all the cases with high blood pressure showed an improvement in this measurement, while pressure remained high in $91 \%$ of those cases where the treatment was continued.

One possible explanation of the hypertensive effects of oral contraceptive steroids may be an alteration in the activity of the renin-angiotensinaldosterone system. This is discussed in the next section.

Effects on Plasma Renin, Renin Substrate, Aldosterone, Corticosterone, and Cortisol

Renin released from the juxtaglomerular cells of the kidney reacts with an alpha-2-globulin fraction of plasma ('renin substrate') to form a decapeptide, angiotensin I, which is further split to an active octapeptide, angiotensin II, by a converting enzyme (Fig. 1). Angiotensin II, which will now be referred to as 'angiotensin', may act on peripheral blood vessels as a vasopressor, directly on the kidney, and on the adrenal cortex to stimulate aldosterone secretion. Techniques now exist to measure some aspect of each of the stage? in this system. The term 'renin activity' is come monly used to designate the amount of angioten sin formed by incubation of plasma, in vitros? under standard conditions, and is a function of both renin concentration and endogenous renine substrate content. Plasma renin concentration on the other hand, must be measured by incu $\Phi^{\circ}$ bation of extracted renin with a standard subo strate preparation, and is independent of endos genous substrate.

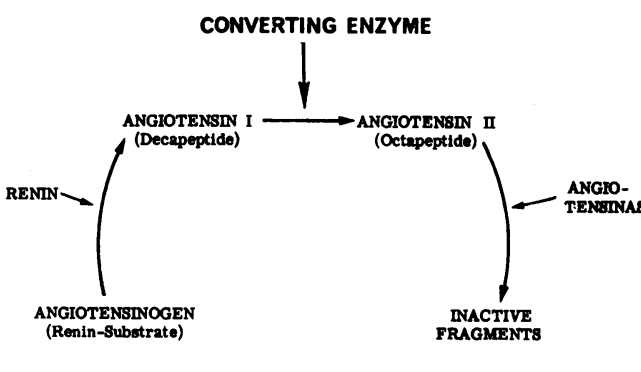

Fig. 1 Formation and destruction of angiotensin in blood.

Oral contraceptive therapy consistently leads t an increase in plasma renin substrate (Helmer an Judson, 1967; Laragh et al, 1967; Newton Sealey, Ledingham, and Laragh, 1968; Skinnero Lumbers, and Symonds, 1969). The maximum? effect develops from four days to two weeks afteo starting treatment, and substrate concentrations return to normal two to four weeks after stopping the drug. Plasma renin activity is raised in the majority of subjects (Laragh et al, 1967; Weing berger et al, 1968; Crane and Harris, 1969) but plasma concentration of the enzyme is not in 3 . creased, apparently irrespective of the brand of contraceptive compound used, and may even faß (Skinner et al, 1969).

The stage of the menstrual cycle at which treat ment commences appears to have no effect on the degree to which renin substrate increases, but rises in renin activity are most marked when the control samples are taken in the first half of the cycle when renin activity is at its lowest (Skinnej et al, 1969).

Increased aldosterone secretion and excretiou rate in subjects given oral contraceptives, ang increased plasma protein binding of aldosterone have been described (Layne, Meyer, Vaishwanar and Pincus, 1962; Laragh et al, 1967; Weinberge et al, 1968; Crane and Harris, 1969), althoug these changes have usually appeared in a minorit $\$$ of cases and have been rapidly reversed on discontinuing treatment. Where such effects have occurred, they have been attributed to the oestr\& genic component of the 'pill' (Crane and Harris 1969). 
Plasma cortisol concentration rises during oral contraceptive therapy (Layne et al, 1962; Burke, 1969; Damkjaer Nielsen, Binder, and Starup, 1969; O'Connell and Welsh, 1969) largely due to an increase in the level of the protein-bound component of the hormone, but as far as we are aware, plasma corticosterone concentration has not previously been measured in this situation.

There follows a preliminary report of a study set up to assess the frequency and degree of blood pressure elevation in a large group of women taking contraceptive tablets, and to examine some of the endocrine changes occurring in a much smaller group.

\section{Methods}

BLOOD PRESSURE

Two brands of oral contraceptive have been chosen: Ovulen as a preparation thought to produce frequent sodium retention, and Norinyl-1 (norethisterone: $1 \mathrm{mg}$, mestranol: $0.05 \mathrm{mg}$ ) as one likely to produce less sodium and water retention. Women wishing to use oral contraception are randomly allocated to one or other of these preparations. Women using a cervical cap or an intrauterine contraceptive device act as controls but are not randomly allocated to these methods. Only women who have not taken oral contraceptives for at least six months before the trial are admitted.

Previous medical history and general examination are conducted by the doctors of the Family Planning Association who also select the method of contraception to be used. The blood pressure and weight are recorded by one doctor who has no knowledge of the women's history, or of the contraceptive technique used. Blood pressure is taken in the sitting position using a standard sphygmomanometer cuff on the same arm at each visit. To reduce observer bias, the sphygmomanometer used is that devised by Rose, Holland, and Crowley (1964). Two readings are taken at an interval of four minutes and the second is taken as the resting blood pressure for the individual. Blood pressure and weight are recorded at the first visit to the clinic before the woman begins to take the contraceptive and at two-monthly intervals thereafter at the same time in the menstrual cycle.

PLASMA RENIN, RENIN SUBSTRATE, AND CORTICOSTEROIDS

Ten women were studied before and between two and six weeks after starting oral contraceptives. Seven took Ovulen and the remainder Norinyl. Blood samples were taken at $8 \mathrm{pm}$ from an antecubital vein with the patient seated. Plasma was separated immediately and stored at $-20^{\circ} \mathrm{C}$. Plasma renin concentration was measured by the method of Brown, Davies, Lever, Robertson, and
Tree (1964), plasma concentrations of aldosterone, corticosterone, and cortisol by a modification of the double isotope derivative technique of Fraser and James (1968), plasma electrolytes by AutoAnalyzer(Technicon, Ltd), and plasma reninsubstrate by the technique of Tree and Weir (1969).

\section{Results}

BLOOD PRESSURE

The study began in March 1969 and is therefore only five months old to date. ${ }^{1}$ So far 92 women have started oral contraceptives (46 on Ovulen, 46 on Norinyl), of whom 69 have been followed for two months and $\mathbf{3 1}$ for four months. Of $\mathbf{3 6}$ women started in the control groups (24 with cervical cap, 12 with intrauterine contraceptive device, IUCD), 23 have been studied for two months and 17 for four months.

No significant changes in systolic or diastolic blood pressure or in weight have been found in any of the four groups so far (Figs. 2, 3, 4). It is, however, intended to increase the number of women participating in the trial and to follow the effects of treatment over a period of at least two years. No individual case of raised blood pressure has yet been noted in the controlled series but two other cases referred to the Glasgow Blood Pressure Clinic are worthy of mention.

The first of these, a 22-year-old woman with a blood pressure of $120 / 80 \mathrm{~mm} \mathrm{Hg}$ before commencing oral contraception (Ovulen), developed a pressure of $180 / 100 \mathrm{~mm} \mathrm{Hg}$ after 20 months of treatment. Six weeks after withdrawal of the drug, her blood pressure had fallen to $135 / 80 \mathrm{~mm} \mathrm{Hg}$. As she was anxious to re-start oral contraception, Norinyl was prescribed and two months later blood pressure remains normal. The second case, a woman of 42 with a previous history of hypertension in her second and third pregnancies and also with a family history of hypertension, complained of tiredness and depression after three months on Norinyl. Blood pressure was then $150 / 85 \mathrm{~mm} \mathrm{Hg}$. Norinyl was replaced by Lyndiol (lynestrenol: $5 \mathrm{mg}$, mestranol: $0.15 \mathrm{mg}$ ) for 10 months by which time blood pressure was $150 / 90$ $\mathrm{mm} \mathrm{Hg}$, rising to $170 / 110 \mathrm{~mm} \mathrm{Hg}$ at 12 months. The oral contraceptive was withdrawn and blood pressure remained high $(180 / 105 \mathrm{~mm} \mathrm{Hg})$ at one month later before subsiding to $140 / 80 \mathrm{~mm} \mathrm{Hg}$ after a further month. The patient's electrocardiogram, chest radiograph, intravenous pyelogram, blood urea level, electrolytes, and midstream urine specimen were all normal.

PLASMA RENIN, RENIN SUBSTRATE, AND CORTICOSTEROIDS

Plasma renin substrate was significantly raised

${ }^{1}$ September 1969. 


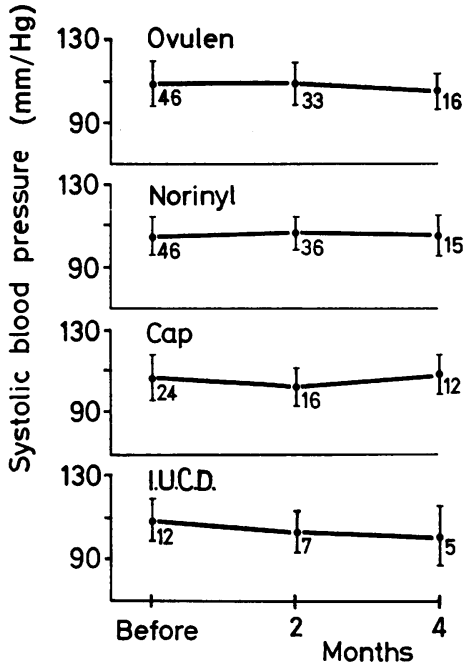

Fig. 2.

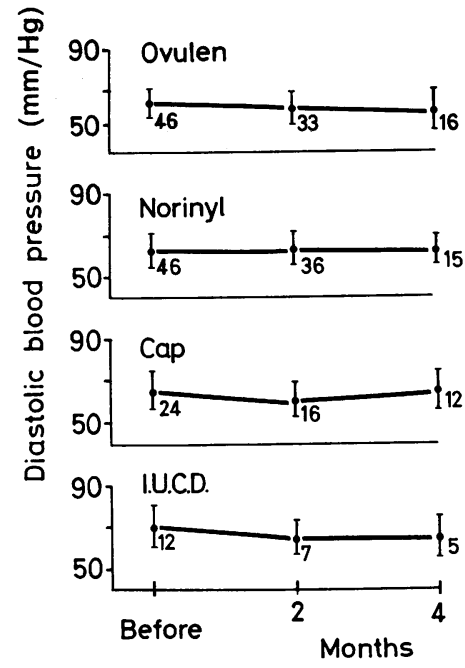

Fig. 3.

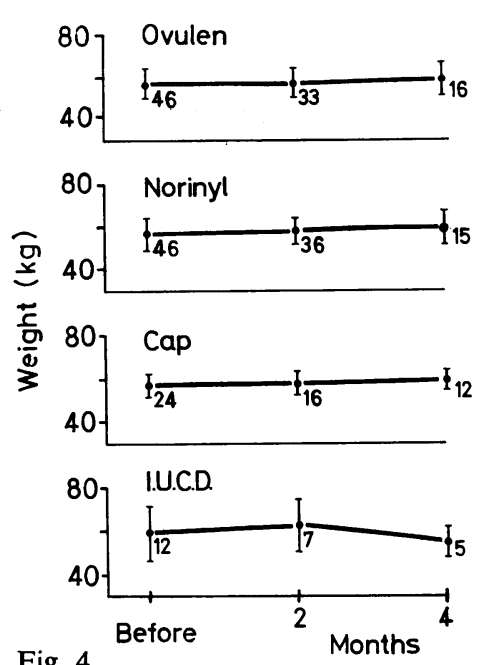

Fig. 4.
Fig. 2 Mean systolic blood pressure before and during oral and mechanical contraception.

Fig. 3 Mean diastolic blood pressure before and during oral and mechanical contraception.

Fig. 4 Mean weight before and during oral and mechanical contraception.

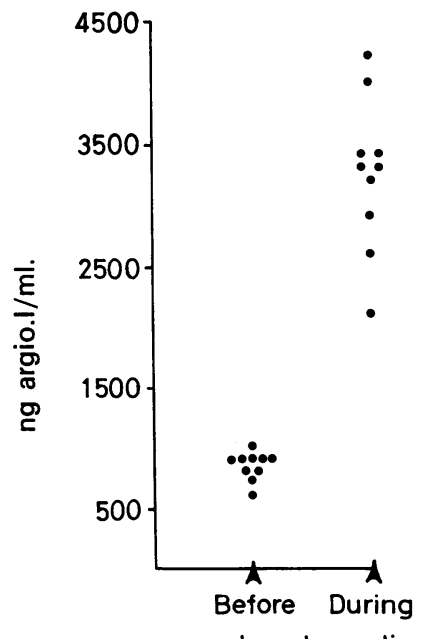

Fig. 5 Plasma renin substrate before and during oral contraception.
$(\mathrm{P}<0.001)$ in all 10 women studied (Fig. with levels up to four times those obtained befoe treatment. No difference was noted between the effects of the brands used. There was no change detectable in concentration over the period of the menstrual cycle.

Plasma renin concentration fell in eight of the 10 subjects (Fig. 6) but this was not statisticaly significant by Student's $t$ test. Although the meag plasma concentrations of aldosterone and corto. costerone were slightly higher after oral contra: ceptive administration, these changes also da not achieve statistical significance (Fig. Conversely, plasma cortisol concentration iff creased in every case, the mean plasma cortiset showing a significant increase $(P<0.01)$, bet in all cases remained within normal limits (Fig. के) although in the upper part of these.

\section{Discussion}

CHANGES IN RENIN, RENIN SUBSTRATE, AN N CORTICOSTEROIDS

These results agree with those of previous workens in that oral contraceptives induce a consistegit rise in the plasma concentration of renin substrate (Helmer and Judson, 1967; Laragh et al, 196\%; Skinner et al, 1969) and that plasma renin coß centration was unchanged or decreased slightly (Skinner et al, 1969). Giving oestrogen has long been known to increase the concentration of various plasma proteins and it is highly probabed that it is this component rather than the progest $\mathcal{F}_{-}$ gen which causes changes in plasma renin sutstrate. Helmer and Griffith (1952) found that ret plasma renin substrate was increased by oestre gen administration and an increase in aldosterone:- 


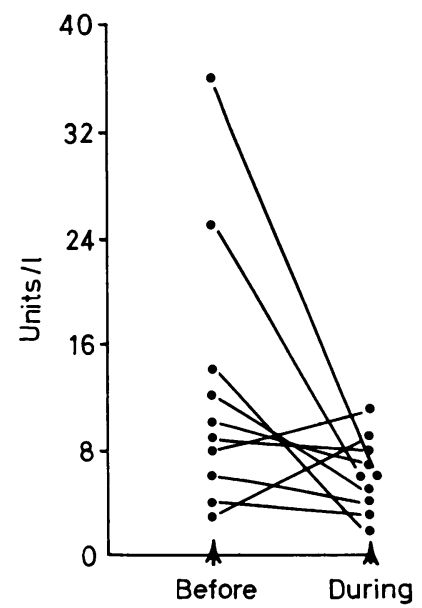

Fig. 6. oral contraception

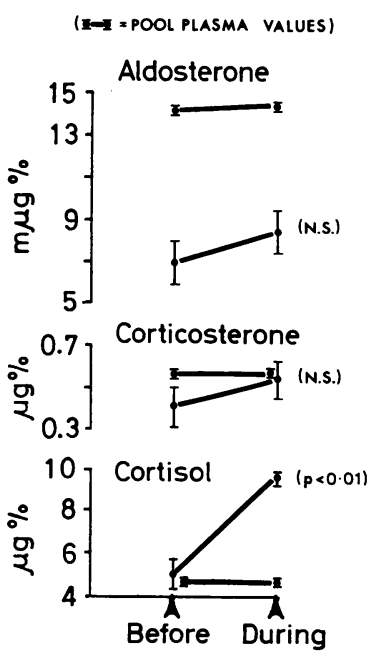

Fig. 7. Treatment
Fig. 6 Plasma renin concentration before and during oral contraception. (It will be noted that two control values were supranormal, ie, $>20$ units/l. Both subjects were symptom-free and no explanation of these high values can be given.)

Fig. 7 Plasma steroid concentrations before and during oral contraception. (Duplicate samples from a large normal human plasma pool were used to determine the reproducibility of the technique of assay.) binding protein (Meyer, Layne, Tait, and Pincus, 1961; Layne et al, 1962) and cortisol-binding protein (Sandberg and Slaunwhite, 1959; Daughaday, Holloszy, and Mariz, 1961; Layne et al, 1962; Doe, Mellinger, Swaim, and Seal, 1967; Keane, Pearson, and Walker, 1969) have been reported in human subjects after similar treatment. These effects have been attributed to an increased hepatic synthesis induced by the steroid hormone. However, plasma renin substrate may increase in renal insufficiency and after bilateral nephrectomy (Cook and Lee, 1965; Laragh et al, 1967) and the possibility of renal involvement in the response of this globulin to oral contraceptives cannot therefore be ignored.

Progesterone may contribute to the increase in substrate (Newton et al, 1968), and, as an aldosterone antagonist (Landau, Bergenstal, Lugibihl, and Kascht, 1955; Landau and Lugibihl, 1961), may possibly also provoke an increase in aldosterone secretion in certain circumstances. Progestogens with an alpha substitute at position $\mathrm{C}-17$, however, may have the reverse effect on aldosterone secretion by promoting sodium retention (Landau, Lugibihl, and Dimick, 1958). The progestogens used in this study were of the latter type and the lack of response of plasma aldosterone in this study may have been due to a balance between the stimulating effects of oestrogen and the suppressing effects of the progestogen.

\section{CHANGES IN BLOOD PRESSURE}

No evidence has so far been obtained in this study that blood pressure is affected by Ovulen or Norinyl but it must be re-emphasized that the study is of an inadequate duration for any firm conclusions to be drawn. That hypertension may occur during periods of treatment with oral contraceptives seems indisputable but reliable assessment of its frequency is still lacking, nor is it yet known whether the majority of women taking oral contraceptives experience small increases in blood pressure or whether this is restricted to a small proportion of susceptible women in whom the rise is severe.

The mechanism by which blood pressure is increased is unclear. Changes in plasma renin or renin substrate concentration do not provide an explanation since they appear to occur irrespective of changes in weight and blood pressure. A family or personal history of hypertension, in renal disease or pregnancy, may predispose towards hypertension during oral contraception in some cases (Woods, 1967; Laragh et al, 1967), although Chiddell (1969) could not find any correlation between toxaemia in pregnancy and hypertension during oral contraception. Weight gain and fluid retention occur in some cases but were not a feature of the two hypertensive cases reported in this study.

It seems unlikely that the rise in blood pressure is associated with an increase in the sensitivity of vascular smooth muscle to the vasoconstrictor effects of angiotensin since sodium balance is not altered, and neither progesterone (Chesley and Tepper, 1967) nor an oestrogen-progesterone mixture (Woods, 1967) appears to alter the pressor response to angiotensin in rats.

Increased angiotensin levels may, in some circumstances, exert a direct inhibitory effect on renin activity (Genest, De Champlain, Veyrat, Boucher, Tremblay, Strong, Kiow, and Aurele, 1964; Vander and Geelhoed, 1965; Klaus and Heizmann, 1967). An impairment or failure of this feedback, such as has been postulated for subjects who develop hypertension during oral contraception (Newton et al, 1968; Skinner et al, 1969), could result in a rise in blood pressure. However, there is no direct evidence for such a hypothesis.

Progesterone causes a rise in blood pressure in 
rabbits (Horrobin, 1968). It is possible that the progestogen component of the oral contraceptive preparation may contribute to the development of hypertension in women, but this cannot account for the infrequency of such an occurrence.

It is hoped that a long-term study, possibly augmented by an investigation of the separate effects of oestrogens and progestogens, may reveal more clearly the mechanism of blood pressure changes and its relationship, if any, to changes in the renin-angiotensin-aldosterone system.

This study was supported by grants from the Council for the Investigation of Fertility Control, the James McCunn Trust, and the Medical Research Council.

The authors would like to express their thanks to the staff of the Glasgow branch of the Family Planning Association for their advice and cooperation in this study and also to Mrs Eleanor Prentice for her valuable assistance in carrying out the plasma renin extractions.

References

Brown, J. J., Davies, D. L., Lever, A. F., Robertson, J. I. S., and Tree, M. (1964). The estimation of renin in human plasma. Biochem. J., 93, 594-600.

Brownrigg, G. M. (1962). Toxemia in hormone-induced pseudo pregnancy. Canad. med. Ass. J., 87, 408-409.

Burke, C. W. (1969). Biologically active cortisol in plasma of oestrogen-treated and normal subjects. Brit. med. J., 2, 798-800.

Chernick, B. A. (1968). Blood pressure and body weight changes during oral contraceptive treatment. Canad. med. Ass. J., 99, 593-599.

Chesley, L. C., and Tepper, I. H. (1967). Effects of progesterone and estrogen on the sensitivity to angiotensin II. J. clin. Endocr., 27, 576.

Chiddell, M. (1969). Personal communication.

Cook, W. F., and Lee, M. R. (1965). The preparation of rabbit renin-substrate for the assay of minute amounts of renin. Biochem. J., 96, 413-418.

Crane, M. G., and Harris, J. J. (1969). Plasma renin activity and aldosterone excretion rate in normal subjects. II. Effect of oral contraceptive agents. J. clin. Endocr., 29, 558-562.

Damkjaer Nielsen, M., Binder, C., and Starup, J. (1969). Urinary excretion of different corticosteroid-metabolites in oral contraception and pregnancy. Acta endorr. (Kbh.), 473-485.

Daughaday, W. H., Holloszy, J., and Marız, I. K. (1961). Binding of corticosteroids by plasma proteins. VI. The binding of cortisol and aldosterone by corticosteroid-binding globulin and by the estrogen-induced binding system of plasma. J. clin. Endocr., 21, 53-61.

Doe, R. P., Mellinger, G. T., Swaim, W. R., and Seal, U. S. (1967) Estrogen dosage effects on serum proteins: a longitudinal study. J. clin. Endocr., 27, 1081-1086.

Dussek, J. E. (1969). Hypertension and the pill. Brit. med. J., 3, 416-417.

Fraser, R., and James, V. H. T. (1968). Double isotope assay of aldosterone, corticosterone and cortisol in human peripheral plasma. J. Endocr., 40, 59-72.

Genest, J., De Champlain, J., Veyrat, R., Boucher, R., Tremblay, G. Y., Strong, C. G., Kiow, E., and Aurele, M. J. (1964). Role of the renin-angiotensin system in various physiological and pathological states. Hypertension, 13, 97-116.

Goodlin, R. C., and Waechter, V. (1969). Oral contraceptives and blood-pressure. Lancet, 1, 1262-1263.

Harris, P. W. R. (1969). Malignant hypertension associated with oral contraceptives. Lancet, 2, 466-467.

Helmer, O. M., and Griffith, R. S. (1952). The effect of the administration of estrogens on the renin-substrate (hypertensinogen) content of rat plasma. Endocrinology, 51, 421 426.

Helmer, O. M., and Judson, W. E. (1967). Influence of high renin substrate levels on renin-angiotensin system in pregnancy, Amer. J. Obstet. Gynec., 99, 9-17.
Horrobin, D. F. (1968). Some effects of long-term progesterocte treatment in rabbits and their relevance to pre-eclampsi Lancet, 1, 170-173.

Keane, P. M., Pearson, J., and Walker, W. H. C. (1969). Bindi characteristics of transcortin in human plasma in normad individuals, pregnancy and liver disease. J. Endocr., 571-579.

Klaus, D., and Heizmann, A. (1967). Zur Regulation der Renins kretion durch Angiotensin. Klin. Wschr., 45, 657-659. O

Kunin, C. M., McCormack, R. C., and Abernathy, J. R. (1969). Oral contraceptives and blood pressure. Arch. intern. med, $123,362-365$.

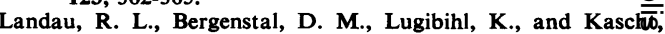
M. E. (1955). The metabolic effects of progesterone man. J. clin. Endocr., 15, 1194-1215.

Landau, R. L., and Lugibihl, K. (1961). The catabolic and natriuretic effects of progesterone in man. Recent Progn. Hormowre Res., 17, 249-292.

Landau, R. L., Lugibihl, K., and Dimick, D. F. (1958). Metabo $\vec{R}$ effects in man of steroids with progestational activity. Ann. N.Y. Acad. Sci., 71, 588-598.

Laragh, J. H., Sealey, J. E., Ledingham, J. G. G., and Newto M. A. (1967). Oral contraceptives. Renin, aldosterone a high blood pressure. J. Amer. med. Ass., 201, 918-922.O

Layne, D. S., Meyer, C. J., Vasshwanar, P. S., and Pincus, P. $_{\text {. }}$ (1962). The secretion and metabolssm of cortisol and ald $\overrightarrow{Q-}$ sterone in normal and in steroid-treated women. $J$. clint. Endocr., 22, 107-118.

Loudon, N. B., and Burton, J. L. (1969). Oral contraceptives anf blood-pressure. Lancet, 2, 217.

Meyer, C. J., Layne, D. S., Tait, J. F., and Pincus, G. (196Q The binding of aldosterone to plasma proteins in normal pregnant and steroid treated women. J. clin. Invest., 40 , 1663-1671.

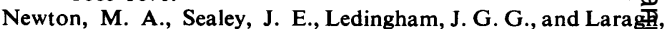
J. H. (1968). High blood pressure and oral contraceptivg. Changes in plasma renin and renin substrate and in aldesterone excretion. Amer. J. Obstet. Gynec., 101, 1037-1045,

O'Connell, M., and Welsh, G. W. III (1969). Unbound plasrog cortisol in pregnant and enovid-E treated women 8 determined by ultrafiltration. J. clin. Endocr., 29, 563-568.

Owen, G. (1966). Hypertension associated with oral contraceptives Canad. med. Ass. J., 95, 167.

Rose, G. A., Holland, W. W., and Crowley, E. A. (1964). sphygmomanometer for epidemio'ogists. Lancet, 1, 2 尊 300.

Sandberg, A. S., and Slaunwhite, W. R., Jr. (1959). Transcorti corticosteroid-binding protein of plasma. II. Levels \& various conditions and the effects of estrogens. $J$. clin Invest., 38, 1290-1297.

Skinner, S. L., Lumbers, E. R., and Symonds, E. M. (1969) Alteration by oral contraceptives of normal menstrua changes in plasma renin activity, concentration and sum strate. Clin. Sci., 36, 67-76.

Tree, M., and Weir, R. J. (1969). In preparation.

Tyson, J. E. A. (1968). Oral contraception and elevated blogd pressure. Amer. J. Obstet. Gynec., 100, 875-876.

Vander, A. J., and Geelhoed, G. W. (1965). Inhibition of ren? secretion by angiotensin II. Proc. Soc. exp. Biol. (N. X), $120,399-405$.

Weinberger, M. H., Dowdy, A. J., Nokes, G. W., and Leutschê J. A. (1968). Reversible increases in plasma renin activit, aldosterone secretion, and blood pressure in women takiog oral contraceptive preparations. (Abstr.) Clin. Res., 16, 150.

Woods, J. W. (1967). Oral contraceptives and hypertensiom Lancet, 2, 653.654. 